\title{
The impact of Working Capital Management on firm profitability in different economic cycles: Evidence from the United Kingdom
}

\author{
Tiago Cruz Gonçalves* • Cristina Gaio • Frederico Robles \\ Advance/CSG ISEG, Lisbon School of Economics \& Management, Universidade de Lisboa, Portugal
}

Received: 20 March 2018

Revised: 21 June 2018

Accepted: 22 June 2018

\begin{abstract}
Literature shows that Working Capital Management (WCM) affects profitability and liquidity. Economic conditions may stress those relationships, especially during economic downturns. We analyze the effects of economic cycle on the relationship between WCM and profitability, using a sample of UK unlisted companies between 2006 and 2014. We find that WCM efficiency increases profitability. This positive impact is even more important during economic downturns. Our results show multi-level effects of WCM on profitability and liquidity constraints, with varying economic conditions. Results matter economically and managerially and highlight the importance of considering WCM as part of overall corporate financial strategy.
\end{abstract}

Keywords: Working Capital Management; firm's profitability; unlisted companies JEL Classification Codes: G31, G32, E32

\section{Introduction}

Finding a balance between profitability and liquidity is probably one of the major challenges of corporate finance management. WCM can play an important role on this balance, and therefore be an important component of corporate finance management.

Prior research suggests that working capital can be an important source of internal funds or substitute to cash (Bates et al. 2009) and that there are many opportunities for improving the efficiency of WCM (Ek and Guerin 2011). However, corporate finance literature mainly focuses on long term finance decisions such as capital structure, dividend policies and capital budgeting. Few studies analyze WCM as a corporate finance strategy that directly impacts firms` profitability and liquidity.

Deloof (2003) provides evidence that, in 1997, investment in working capital represents about $27 \%$ of total assets of Belgium firms and conclude that WCM is a crucial component of their

\footnotetext{
*Corresponding author. E-mail: tiago@iseg.ulisboa.pt.

Citation: Gonçalves, T. C., Gaio, C., and Robles, F. (2018) The impact of working capital management on firm profitability in different economic cycles: Evidence from the United Kingdom, Economics and Business Letters, $7(2), 70-75$.
} 
financial strategy. According to EY (2016), companies have huge opportunities to improve WCM. Results from this study indicate that, in 2015, the top 2000 US and European companies have as much as US\$1.2 trillion working capital amount in excess, equivalent to $7 \%$ of their combined sales.

Previous studies that analyze the relationship between profitability and WCM provide evidence that an efficient WCM improves profitability (Aktas et al., 2015; and Deloof, 2003; Enqvist et al., 2014). However, most of them focus on large and listed firms and WCM is probably even more important in the case of small and medium-size firms as they do not have access to stock markets and have limited access to bank's financing (Baños-Caballero et al, 2010).

Therefore, we investigate the relation between WCM and profitability for a sample of 400 UK unlisted firms for the 2006-2014 period. Because the efficiency of WCM depends on the efficiency of the management of the working capital components - accounts receivable, inventories and accounts payable, we also examine the role of each component on profitability.

In addition, during the study period Europe was affected by a massive financial crisis, which may reinforce the role of WCM as a financial strategy, we also analyze the effects of economic cycles on the relation between WCM and profitability. In fact, an efficient WCM may play a very important role during financial crises in unlisted firms since banks, their main financing source, place more hurdles to lend money.

This study contributes to the literature in at least two ways. First, it expands the scarce literature on the relation between WCM and profitability in unlisted firms ${ }^{1}$, since most of the existing studies focus on listed firms. Second, it expands the also scarce existing literature on the role of economic cycles on the relation between WCM and profitability.

The paper is organized as follows. Section 2 presents the methodology and describes the data. Section 3 presents and discusses the empirical results. Finally, Section 4 concludes.

\section{Methodology and data}

Working capital is defined as the difference between current assets and current liabilities. We use the cash conversion cycle (CCC) as a measure of WCM. By using CCC as the proxy for WCM, we recognize not only the life expectancies of working capital components but also the fact that production, distribution and collection are not instantaneous but come with a time lag (Enqvist et al., 2014). CCC is computed as:

$$
C C C_{i t}=A R_{i t}+I N V_{i t}-A P_{i t}
$$

$\mathrm{AR}$ is the accounts receivables days, equal to (Account receivables / Sales) x 365; INV is inventory turnover days, equal to (Inventory / Cost of Goods Sold) x 365; and AP is accounts payable days, equal to (Accounts Payables / Cost of Goods sold) x 365 .

We use the return on assets (ROA) and the gross operating income (GOI) as proxies for firm's profitability. ROA is computed as Net Income divided by Total Assets and GOI is Earnings before Interests and Taxes divided by Total Operating Assets.

Following Enqvist et al. (2014), Lazaridis and Tryfondis (2006) and Deloof (2003), we estimate the following regression model:

$$
\begin{gathered}
R O A_{i t}(G O I)=\beta 0+\beta 1 C C C_{i t}+\beta 2 C R_{i t}+\beta 3 D E B T_{i t}+\beta 4 S A L E S_{i t}+ \\
\beta 5 D D+\beta 6 D B+\beta 7\left(D D^{*} C C C_{i t}\right)+\beta 8\left(D B^{*} C C C_{i t}\right)+\mu_{i t}
\end{gathered}
$$

\footnotetext{
${ }^{1}$ Demirguc-Kunt et al. (2015), using data from 277.000 firms across 79 countries, evaluated the impact of the global financial crisis on firms' debt for the period 2004-11. They showed that leverage and debt maturity declined, mostly for firms in countries with shallower banking systems and/ or that suffered the most severe shocks, but also for countries that did not experience a crisis. Results were most prevalent for unlisted firms, and, among those, for small and medium enterprises. In contrast, publicly listed firms exhibited weaker evidence of a significant impact on debt financing access. The authors argued for a tightening of credit based on uncertainty or risk increase.
} 
$\mathrm{CR}$ is current ratio, a measure of liquidity, is computed as current assets divided by current liabilities; DEBT is debt ratio, computed as the sum of short-term loans and long-term debt divided by total assets; SALES is the natural logarithm of sales; DD is a dummy for downturn period and DB a dummy for boom period. Industry dummies are included to control for the impact of industry differences on profitability and WCM.

Based on the GDP growth between 2006 and 2014 (Figure 1), we considered the years with negative growth as downturn periods; the years with GDP growth above $2.5 \%$ as the boom periods and the remaining years as normal periods.

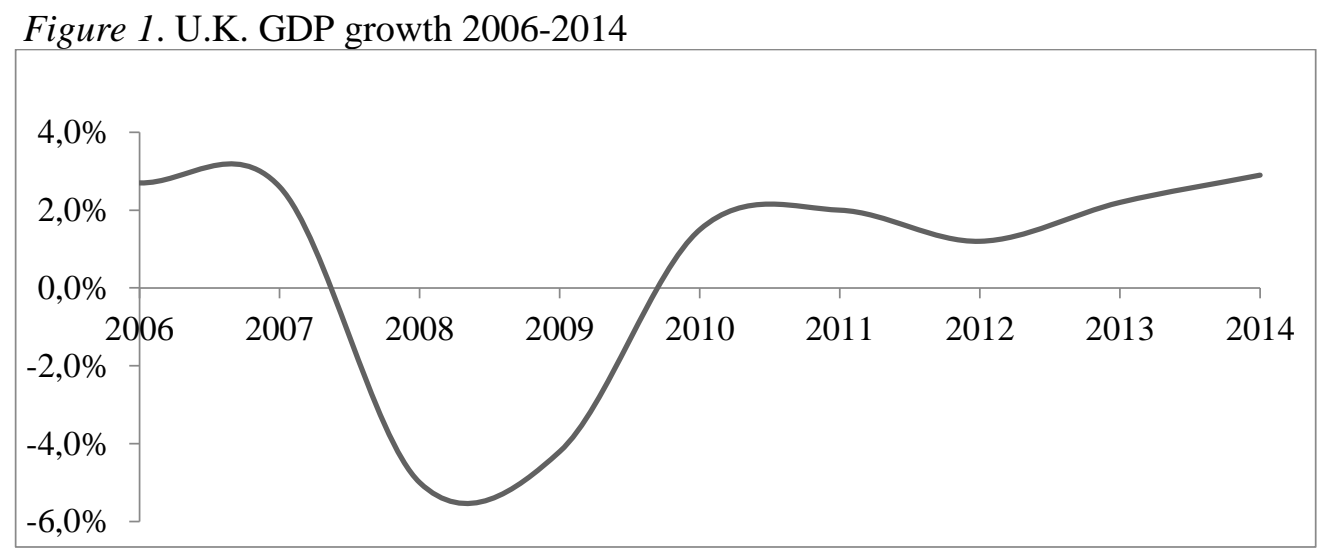

Source: http://ec.europa.eu/eurostat.

Indeed, economy-wide fluctuations exogenous to operations may affect products' demand, financial decisions and working capital practices and 2007-2008 crises has brought renewed focus on WCM (Enqvist et al., 2014). An efficient WCM may play a very important role during financial crises, especially in unlisted firms since their main financing partner, banks, fighting against the crisis, place more hurdles to lend money.

Finally, to check the influence that each component of the CCC on profitability, we also estimate regression model (2) considering each CCC component: AR, INV and AP instead of CCC.

Following previous studies, we exclude financial institutions and firms with less than 50 million EUR of total assets ${ }^{2}$, in order to focus the analysis on the medium and large firms (Deloof, 2003; Enqvist et al., 2014). The final sample includes 400 firms and a total of 29380 firm-year observations. All data are from database Amadeus.

\section{Results}

Descriptive statistics results (untabulated) indicate that, on average, the UK unlisted firm has a ROA of $4.2 \%$, a GOI of $16 \%$, a CR of 1.66 and $27 \%$ of its assets are financed by Debt. The means of CCC, AR, AP and INV are 13.3, 32.7, 67.0, and 47.6 days, respectively. It suggests that UK unlisted firms shorter trade credit to customers and delay payments to creditors, which is a characteristic of an aggressive WCM policy.

Table 1 presents the results of our main analysis. The results show a negative and statistically significant relation between CCC and both ROA (Panel A) and GOI (Panel B). This result suggests that firms can increase profitability by reducing the length of its $\mathrm{CCC}$, which is in line with previous studies (Enqvist et al. 2014; Deloof, 2003; Lazaridis \& Tryfondis, 2006).

\footnotetext{
${ }^{2}$ Based on the work of Demirguc-Kunt et al. (2015), we argue for differential effects on listed and privately held firms regarding the impact of WC management under different business cycles. Since the former study showed that there is an additional debt access effect for small and medium enterprises, we chose to rule out the size effect and focus our conclusions on (un)listing impact.
} 
Table 1. Relationship between Profitability and Working Capital Management.

\begin{tabular}{|c|c|c|c|c|c|c|c|c|}
\hline \multicolumn{9}{|c|}{ Panel A: ROA } \\
\hline$\beta 1$ & $\beta 2$ & $\beta 3$ & $\beta 4$ & $\beta 5$ & $\beta 6$ & $\beta 7$ & $\beta 8$ & Adj $R^{2}$ No. Obs. \\
\hline$-.008 * * *$ & .113 & $-8.934 * * *$ & $-.335 * * *$ & $-1.041 *$ & $.635 * *$ & $-.006 * *$ & $-.005 * * 0$ & 29380 \\
\hline \multicolumn{9}{|c|}{ Panel B: GOI } \\
\hline$\beta 1$ & $\beta 2$ & $\beta 3$ & $\beta 4$ & $\beta 5$ & $\beta 6$ & $\beta 7$ & $\beta 8$ & Adj $R^{2}$ No. Obs. \\
\hline$-.002 * *$ & $.103^{* * *}$ & $.567 * * *$ & $.646^{* * *}$ & $-.215 * * *$ & $.244 * * *$ & $-.215 * * *$ & $-.001 * *$ & 29380 \\
\hline
\end{tabular}

Note: This table presents results from estimate regression model 2 from the years of 2006 to 2014; *, **, *** denotes significance levels at $10 \%, 5 \%$ and $1 \%$, respectively.

ROA decreases close to $0,5 \%$ when CCC increases one standard deviation, thus leading to a statistically and economically significant relationship between those variables. Furthermore, if we consider the marginal effect of the economic cycle on that association, we find a statistically significant increase on that inverse relationship. During both economic booms and downturns, ROA decreases incrementally for an increase in CCC. Economically, one standard deviation increase in $\mathrm{CCC}$, will associate with a further $0,32 \%$ decrease in ROA during downturns, and $0,27 \%$ during economic booms. We found both marginal effects of extreme economic cycles to be statistically significant on ROA, although direction and size are similar.

In terms of GOI, results are quite similar. However, the coefficient on CCC*DD is now statistically significant at the $1 \%$ level and much higher than that of $\mathrm{CCC}^{*} \mathrm{DB}$, which suggest that the marginal effect of WCM on profitability is more severe during the downturns periods.

Overall the results on the role of economic cycles show that the effect of WCM on profitability is more pronounced in economic downturns than on economic booms, suggesting that although WCM matters in all economic cycles, it is particularly relevant during poor economic periods.

Table 2 summarizes the results when we estimate the regression (2) with each CCC component: AR, INV and AP. The results show a negative statistically significant relationship between profitability and AR, which mean that more profitable firms have lower AR. This result may indicate that UK unlisted firms increase incentives for sales, by extending account receivables days, in order to increase revenues.

Table 2. Relationship between Profitability and Working Capital Management Components.

\begin{tabular}{|c|c|c|c|c|c|c|c|c|c|c|}
\hline \multicolumn{11}{|c|}{ Panel A: ROA } \\
\hline & $\beta 1$ & $\beta 2$ & $\beta 3$ & $\beta 4$ & $\beta 5$ & $\beta 6$ & $\beta 7$ & $\beta 8$ & $\operatorname{Adj} R^{2}$ & No. Obs. \\
\hline$A R$ & $.044 * * *$ & .07 & $-9.463 * * *$ & $-.442 * * *$ & .279 & $.758 * * *$ & $-.027^{*}$ & $-.036 * * *$ & 0.41 & 29380 \\
\hline$I N V$ & -.001 & .142 & $-8.793 * * *$ & $-.346 * * *$ & .470 & $.613^{*}$ & -.002 & -.001 & 0.38 & 29380 \\
\hline$A P$ & $.006^{*}$ & .095 & $-8.887 * * *$ & $-.275^{* *}$ & $-.866 * *$ & .293 & .005 & .004 & 0.41 & 29380 \\
\hline \multicolumn{11}{|c|}{ Panel B: GOI } \\
\hline & $\beta 1$ & $\beta 2$ & $\beta 3$ & $\beta 4$ & $\beta 5$ & $\beta 6$ & $\beta 7$ & $\beta 8$ & $A d j R^{2}$ & No. Obs. \\
\hline$A R$ & $-.005 * * *$ & $.094 * * *$ & $.530 * * *$ & $.636 * * *$ & .002 & $.454 * * *$ & $-.007 * *$ & $-.007 * * *$ & 0.57 & 29380 \\
\hline$I N V$ & .004 & .142 & $-8.793 * * *$ & $-.346^{* * *}$ & $-.137 *$ & $.218 * *$ & $-.002 * *$ & .000 & 0.38 & 29380 \\
\hline$A P$ & $.003 * * *$ & $.088 * * *$ & $.608 * * *$ & $.675^{* * *}$ & $-.225^{*}$ & $.143 * *$ & -.007 & $.001 * * *$ & 0.59 & 29380 \\
\hline
\end{tabular}

Note: This table presents results from estimate the regression model 2, for each CCC component: AR, INV and AP, from the years of 2006 to 2014 ; $^{*}$, **, *** denotes significance levels at $10 \%, 5 \%$ and $1 \%$, respectively. 
Additionally, incremental effects of extreme economic cycles on profitability are particularly relevant (and statistically significant) regarding trade receivables. Although an increase in days of sales outstanding is associated with a marginal decrease in ROA and GOI, both for economic downturns and booms, the incremental decrease is more severe for favorable economic cycles.

In terms of inventory conversion period, the results show a negative but statistically insignificant relationship between profitability and INV. Only in poor economic states it seems that inventory turnover impacts negatively profitability, measured as GOI. The coefficient on INV is negative and significant at 5\% level, suggesting that UK unlisted firms shorten their inventory conversion period in order to enhance their profitability during economic downturns periods. By having low levels of inventories, firms have lower inventory keeping costs and so can increase profitability, but only in downward periods. It seems that during normal and boom periods inventory turnover does not affect profitability.

Finally, the results show a positive and significant relationship between profitability and AP, which suggests that firms can increase profitability by extending the time to pay their bills. It seems that UK unlisted companies use trade credit as a source of financing instead of taking advantage of possible cash discounts. Regarding the influence of economic states on the relation between profitability account payables, we only find statistical significant results for GOI, and only within the boom periods, suggesting that the effect of accounts payable on profitability is more pronounced in economic booms.

\section{Concluding remarks}

Working Capital Management is usually considered by corporate financial executives as a very important determinant of firm`s profitability (Lamberson, 1995). However, few studies have analyzed WCM as part of the overall financial strategy and how an efficient WCM improves firm`s profitability.

We documented a negative and significant relationship between profitability and WCM efficiency, which suggest that firms may improve profitability by managing working capital efficiently. This relationship is also economically significant. For example, return on assets decreases close to $0,5 \%$ when the length of cash convertible cycle, our measure of WCM, increases one standard deviation. This result suggests that firms should pay attention to working capital practices because they directly impact profitability.

Results on the role of economic cycles on the inverse relationship between profitability and WCM efficiency, indicates an incremental increase in both downturn and boom economic cycles, being, however, more severe in downturn ones. Therefore, we may conclude that an efficient WCM is even more important during poor economic states, which reinforces the role of WCM during financial crises.

Our results also suggest that the incremental effects of extreme economic cycles on profitability are particularly relevant with respect to accounts receivables, more so in boom economic cycles. Indeed, we find evidence that during these cycles, increasing customer trade credit has a negative incremental impact very significant in profitability.

Overall, our results suggest that profitability can be enhanced if firms manage their working capital in a more efficient way, meaning that firms can create value for their shareholders through an efficient Working Capital Management. This is especially important during downturn economic cycles. An efficient management would provide internally-generated funds which could be used in more profitable investment opportunities, highlighting the importance of considering Working Capital Management as part of overall corporate financial strategy. 


\section{Acknowledgements}

FCT- Fundação para a Ciência e Tecnologia (Portugal), national funding through research grant (UID/SOC/04521/2013).

\section{References}

Aktas, N., Croci, E., and Petmezas, D. (2015) Is working capital management value-enhancing? Evidence from firm performance and investments, Journal of Corporate Finance, 30, 98113.

Baños-Caballero, S., García-Teruel, P., and Martínez-Solano, P. (2010) Working capital management in SMEs, Accounting and Finance, 50, 511-527.

Bates, T. W., Kahle, K. M. \& Stulz, R. M. (2009) Why do U.S. firms hold so much more cash than they used to?, Journal of Finance, 64, 1985-2022.

Deloof, M. (2003) Does Working Capital Management Affect Profitability of Belgian Firms?, Journal of Business Finance \& Accounting, 30, 573-587.

Demirguc-Kunt, A., Martinez Peria, M., and Tressel, T. (2015). The impact of the global financial crisis on firms' capital structure (No. 7522). The World Bank.

Ek, R., and Guerin, S. (2011) Is there a right level of working capital?, Journal of Corporate Treasury Management, 4, 137-149.

Enqvist, J., Graham, M., and Nikkinen, J. (2014) The Impact of Working Capital Management on Firm Profitability in Different Business Cycles: Evidence from Finland, Research in International Business and Finance, 32, 36-49.

Ernest and Young (2016) Working Capital Management Report 2016.

Lamberson. M. (1995) Changes in Working Capital of Small Firms in Relation to Changes in Economic Activity, Mid-American Journal of Business, 19, 45-50.

Lazaridis, I., and Tryfonidis, D., (2006) Relationship Between Working Capital Management and Profitability of Listed Companies in the Athens Stock Exchange, Journal of Financial Management \& Analysis, 19, 26-36. 